\title{
Cemented and Cementless Total Hip Replacement
}

\author{
Critical Analysis and Comparison of Clinical and Radiological Results of 182 Cases Operated \\ in Al Razi Hospital, Kuwait
}

\section{Wieslaw Pospula Tarek Abu Noor Tarek Roshdy Ali Al Mukaimi}

Department of Orthopedics, Al Razi Hospital, Kuwait

\section{Key Words \\ Total hip replacement, cemented and cementless $\cdot$ Total hip replacement, clinical and radiological results}

\begin{abstract}
Objective: In this study we present the results of a series of cemented Exeter and cementless Zweymüller implants. Subject and Methods: Eighty-seven cemented and 95 cementless hip replacements for different hip pathologies were followed for an average period of 36 months for cementless and 60 months for cemented cases. Clinical results were calculated using the Merle d'Aubigne score. The orientation of the prosthetic components and the fixation of the cup and stem were analyzed. The clinical and radiological results were compared using statistical methods. Results: In the average period of 36 months in cementless and 60 months in cemented hip replacements the clinical results improved significantly when compared with the preoperative score $(p<0.05)$. Sixty-seven cemented acetabular cups $(77.1 \%)$ were in the desired position $\left(30-50^{\circ}\right)$ and 20 cemented cups (22.9\%) were outside this range. Seventy-six cups (80\%) were in the desired degree of abduction and 19 (20\%) were outside this range. All cups except 1 were anteverted or neutral. Of the femoral stems, 173 were in the neutral position, 5 in the valgus and 4 in the varus position. Cemented cups were more commonly loose and cemented and cementless stems did equally well. No significant differences in rate of complications were found. Conclusion: Cementless acetabular im-
\end{abstract}

plants had better clinical results and a lower loosening rate at 3 years of follow-up compared to cemented implants at 5 years of follow-up. The cemented femoral implants were equally stable compared to the cementless ones.

Copyright $\odot 2008$ S. Karger AG, Basel

\section{Introduction}

Total hip replacement has been a well-established treatment method for a spectrum of hip problems including primary and secondary osteoarthritis, avascular necrosis and hip fracture [1]. Although there is general belief that cementless prosthesis has a better outcome and long-term prognosis, especially in young active patients, it has not been proved by longitudinal studies of results comparing new-generation cemented with cementless implants $[2,3]$. In the published series cemented, cementless and hybrid implants have been discussed $[4,5]$. The objective of this study is to evaluate and compare short-term clinical and radiological results of cemented Exeter total hip replacement with cementless Zweymüller implants.

\section{Patients and Methods}

Between 1994 and 2004 there were 185 total hip replacements done by the senior author (W.P.) in Al Razi Hospital, Kuwait. Three patients were lost to follow-up, so the remaining 182 cases were clinically and radiologically followed up: 87 cemented Ex-

\section{KARGER}

Fax +4161306 1234

E-Mail karger@karger.ch

www.karger.com (c) 2008 S. Karger AG, Basel

1011-7571/08/0173-0239\$24.50/0

Accessible online at:

www.karger.com/mpp
Wieslaw Pospula

Al Razi Orthopedic Hospital

PO Box 4235, 13043 Safat (Kuwait)

Tel. +965 9862485 , Fax +965 4822240

E-Mail pospulawieslaw@hotmail.com 
Table 1. Cases, gender, age and follow-up period

\begin{tabular}{llll}
\hline & Cemented & Cementless & Total \\
\hline Patients & 76 & 89 & 165 \\
Hips & 87 & 95 & 182 \\
Gender/hips & & & \\
$\quad$ Males & $29 / 32$ & $48 / 50$ & $77 / 82$ \\
$\quad$ Females & $47 / 55$ & $41 / 45$ & $88 / 100$ \\
Age, years & $53.7(22-104)^{*}$ & $46.7(16-76)^{*}$ & \\
Follow-up, months & $60(24-156)$ & $36(24-84)$ & \\
\hline
\end{tabular}

${ }^{*} \mathrm{p}<0.01$.

Table 2. Radiological results

\begin{tabular}{lcc}
\hline & Cemented & Cementless \\
\hline $\begin{array}{l}\text { Cup inclination (abduction) } \\
<30^{\circ}\end{array}$ & $12(13.8)$ & $8(8)$ \\
$30-50^{\circ}$ & $67(77)$ & $76(80.5)$ \\
$\quad>50^{\circ}$ & $8(9.2)$ & $11(11.5)$ \\
Cup version & & \\
$\quad$ Anteversion & $85(97.8)$ & $83(87.4)$ \\
$\quad$ Neutral & $1(1.1)$ & $12(12.6)$ \\
$\quad$ Retroversion & $1(1.1)$ & 0 \\
Stem frontal & & \\
$\quad$ Neutral & $79(89.9)$ & $83(87.5)$ \\
Varus & $6(10.1)$ & $7(7.3)$ \\
Valgus & 0 & $5(5.2)$ \\
\hline
\end{tabular}

Figures in parentheses are percentages.

eter (Stryker-Howmedica, UK) and 95 cementless Zweymüller (Plus Orthopedics, Rotkreuz, Switzerland) hip replacements. In the cemented group there were 29 males and 47 females with an average age of 53.7 years, whereas the cementless group included 48 males and 41 females with an average age of 46.7 years. In the group of cemented hip replacement there were 11 bilateral cases ( 3 males and 8 females), while in the cementless group there were 6 bilateral cases ( 2 males and 4 females). The patients who had a cementless hip replacement were significantly younger (16-76 years) than those who had cemented implants (22-104 years). The average follow-up of the patients who had cemented implants was 60 months and that of the patients who had cementless implants was 36 months (table 1). All cemented hip replacements except 1 case were operated from the posterolateral approach. All cementless hips except 2 cases were done through the transgluteal approach. All were performed in a standard operating theater without laminar flow and exhaust system for the surgical team. All patients received prophylactic antibiotics prior to the skin incision and continued for $48 \mathrm{~h}$. Clinical assessment was done accord- ing to the Merle d'Aubigne clinical score [6] and radiological assessment including cup and stem integration followed DeLee and Charnley, Gruen and Engh and Massin criteria for the acetabular cup and Gruen criteria for femoral stem [7-10]. The geometrical position of the cup and stem was assessed on the plain X-ray of both hips. Inclination was determined as the angle between the long axis of the oval cup outline and the line joining teardrop on both sides. If teardrop could not be identified, the bi-ischial line was used as the reference. The anteversion was assessed qualitatively using the geometrical Pettersson method [11], where the short axis of the oval cup outline on the X-ray centered over the symphysis pubis and the short axis of the cup outline on the X-ray centered over the operated hip were compared. When the diameter of the short axis of the cup outline on the anteroposterior pelvis centered on the symphysis pubis was shorter than the same diameter on the anteroposterior pelvis centered over the assessed hip, the cup was considered anteverted. If the opposite was found, the cup was regarded as retroverted. If the diameters were equal, the cup was considered neutral. The position of the stem in the frontal plane was assessed comparing the long axis of the stem and the long axis of the femur. The neutral, valgus and varus positions of the stem could be defined. Antetorsion of the stem was not assessed. Statistical analysis was done using the SPSS package. Numerical data were correlated with the independent-sample $t$ test and categorical data were analyzed using $\chi^{2}$ test. Statistical significance was determined at a minimum $\mathrm{p}$ value $<0.05$.

\section{Results}

The average preoperative Merle d'Aubigne clinical score was 10.2 points for the cemented group and 11.5 for the cementless group, indicating that the patients with cementless implant had a better average preoperative clinical score. At the final follow-up of 60 months patients with cemented implants had an average score of 16.6 points, compared to those who had cementless implants with an average score of 17.3 points at 36 months. The difference between preoperative and final clinical scores was statistically significant in both groups of patients with $\mathrm{p}<0.05$.

The radiological results are given in table 2 . The abduction angle of the acetabular component was within the desired angle (between 30 and $50^{\circ}$ ) in 67 cemented cases (76\%) compared to 76 cases $(80.5 \%)$ in cementless group. It was below $30^{\circ}$ of abduction in 12 cemented cases (13.5\%) and in 8 cementless cases (8\%). Similarly the cup was implanted above $50^{\circ}$ of abduction in $8(9.1 \%)$ and in $11(11.5 \%)$, respectively. The components were anteverted in $85(97.8 \%)$ and $83(87.4 \%)$ in the cemented and cementless groups, respectively. The femoral stem was in the neutral position in the anteroposterior plane in 81 cases of cemented implants (93.1\%) and in 83 (87.5\%) of the cementless cases. 
Analysis of implant/cement/bone and implant/bone interfaces resulted in the following assessment of implant stability: 77 cemented implants (88.5\%) were stable. In 2 cases $(2.2 \%)$ the stem and cup were possibly loose, in 5 cases $(5.7 \%)$ there was definite isolated cup loosening and in 3 cases (3.4\%) definite isolated stem loosening. The corresponding values in the cementless group were the following: 93 implants (97.8\%) were stable, 1 isolated cup (1.1\%) and 1 isolated stem (1.1\%) were possibly loose and 1 isolated cup (1.1\%) and 1 isolated stem (1.1\%) were definitely loose (table 3). Different aspects of the clinical and radiological outcome of patients operated through the transgluteal approach were slightly better than in patients operated from the posterolateral approach (17.3 and 16.7, $\mathrm{p}<0.05)$. The cup inclination did not affect the cup integration in either group ( $p>0.05$; table 4$)$. However when cemented and cementless cups were compared, the loosening rate of cemented cups was significantly higher than the same rate in cementless cups, with $\mathrm{p}<$ 0.05 (table 3). Statistical radioclinical correlations revealed that the varus position of the stem was significantly related to loosening of the stem. This applied to both cemented and cementless implants, with $\mathrm{p}<0.01$ in both groups (table 5).

Complications included infection in 5 cases (4 in cemented and 1 in cementless), dislocation in 7 cases ( 4 in cemented and 3 in cementless), intraoperative greater trochanter fracture in 9 cases ( 4 in cemented and 5 in cementless), postoperative periprosthetic fractures in 4 cases (only in cemented cases), femoral nerve palsy in 2 cases ( 1 in cemented and 1 in cementless) and sciatic nerve palsy in 1 cemented case. Statistical analysis did not reveal significant differences in type and frequency of complications between cemented and cementless cases ( $\mathrm{p}>$ 0.05).

\section{Discussion}

In this retrospective comparative analysis we tried to answer the question which implant has a better result. The limitations of this study include the very fact that it is a retrospective study and that the 2 groups have different average follow-up periods; cemented: 60 months, and cementless: 36 months. Yet certain inferences can be made. The diagnostic characteristics of the presented material reveal significant differences when compared with similar groups of patients operated in Europe [12]. In the present study primary osteoarthritis occurred only in $12.6 \%$ of the cases compared to $61.5 \%$ in European
Table 3. Implant integration

\begin{tabular}{lcc}
\hline & Cemented & Cementless \\
\hline Cup and stem integrated & $77(88.5)$ & $90(95.7)$ \\
Possible cup and stem loosening & $2(2.3)$ & $2(2.1)$ \\
Definite isolated cup loosening & $5(5.7)^{*}$ & $1(1.1)^{*}$ \\
Definite isolated stem loosening & $3(3.5)$ & $1(1.1)$ \\
\hline
\end{tabular}

Figures in parentheses are percentages. ${ }^{*} \mathrm{p}<0.05$.

Table 4. Acetabular angle and cup integrity (Pearson $\left.\chi^{2}\right)$

\begin{tabular}{lcll}
\hline Cup inclination & Stable cases & Possibly loose cases & Loose cases \\
\hline$<30^{\circ}$ & 20 & 0 & 0 \\
$30-50^{\circ}$ & 115 & 2 & 8 \\
$>50^{\circ}$ & 24 & 0 & 1 \\
\hline \multicolumn{2}{c}{$\mathrm{p}=0.684$, not significant. } \\
\hline
\end{tabular}

Table 5. Stem alignment and stem integrity (Pearson $\chi^{2}$ )

\begin{tabular}{lrll}
\hline Stem alignment & Stable cases & Possibly loose cases & Loose cases \\
\hline Neutral & 147 & 0 & 3 \\
Varus & 10 & $3^{*}$ & $1^{*}$ \\
Valgus & 5 & 0 & 0 \\
\hline
\end{tabular}

${ }^{*} \mathrm{p}<0.01$

studies. The incidence of primary and secondary avascular necrosis as a preoperative diagnosis was $33.2 \%$ in our study compared to $12.8 \%$ in European studies. Hip dysplasia was the diagnosis in $3 \%$ and rheumatoid disease in $16 \%$ in this study compared to 12.8 and $3 \%$ of the European cases, respectively. These variations may reflect genetic and lifestyle differences between European and Asian populations. Similar differences have been reported by other authors [2]. Comparisons of outcomes between cemented and cementless hip implants have been done previously. In 1 study the clinical and radiological results of cemented and cementless hip replacement in the same patient were compared using the same criteria and no differences were found at the last follow-up on average 7.8 years after surgery. In another prospective 
randomized study the same implant was used with cement or without cement $[13,14]$. We believe that cemented and cementless femoral stems may give similar results and this is also supported by previous observation [12]. Less predictable results of the cemented cup were observed in longer follow-up series $[15,16]$ and this finding was confirmed in our study with a relatively high loosening rate. Improvement in the cementing technique is less likely to reduce the loosening rate of the cup when compared with the stem in historical series, due to the difficulty of pressurization of acetabular bone cement compared to the third-generation femoral cementing technique. Because of this fact cementless fixation of the acetabular component has been more frequent in our hospital during the last 5 years. The surgical approach slightly affected the results of our patients. Patients operated from the posterior approach had slightly inferior results compared to patients who had a direct lateral (or transgluteal) approach. In the study of Zimmerman et al. [4] a slight difference in results in favor of the direct lateral approach was observed, although this difference was not statistically significant. In our study a comparison of different aspects of clinical and radiological results revealed that cementless implants have a better outcome than the cemented implants regarding overall clinical scores and these differences were statistically significant. The loosening rate of the cementless cup was significantly lower than that of the cemented cups. There were no significant differences in rate of loosening of the stem. The dislocation rate was similar in the cemented (4 cases, $4.5 \%$ ) and cementless (3 cases, $3.1 \%$ ) groups and the prevalence of dislocation did not differ in relation to the surgical approach, i.e. there were 4 dislocations (4.5\%) in the posterior approach and 3 dislocations (3.1.\%) in the transgluteal approach and these differences were not statistically significant. The reported incidence of dislocation after total hip replacement ranges from 1 to $15 \%$ [17]. Clinical and experimental studies indicate that dislocation after total hip replacement is a complex and multifactorial problem. Orientation of the implant, soft tissue tension, surgical approach and size of the head are among the most significant factors. Although there is common belief that the inclination and version of the cup are the most important risk factor in dislocation, it was not proved in any of the presented studies [18-21]. There was no definitive coincidence between cup position or surgical approach and dislocation in our patients. Infection is one of the most disastrous complications after total hip replacement. The incidence of infection after hip replacement in the last decade has been reported to be between
0.1 and $1 \%$ and up to $29 \%$ in earlier series [22-25]. In our series there were 4 cases (4.5\%) of deep infection in cemented hip replacement necessitating surgical debridement in 2 cases and revision in 2 cases. In the cementless group there was 1 case $(1.1 \%)$ of infection necessitating revision. This rate of infection is above the reported incidence in the recent literature. Infection after hip replacement is also a multifactorial problem including surgical technique, time of surgery, surgical environment and many other factors. Improvement in surgical technique and surgical environment has reduced the rate of infection below $1 \%$ according to many published studies. We believe that the higher rate of infection in our series was due to the suboptimal surgical environment. Peripheral nerve palsy, a third serious complication of total hip replacement, occurred in 3 cases $(1.3 \%)$ compared to the reported incidence of this complication ranging from 0.3 to $3.7 \%$ [26]. In 2 cases of cementless implant there was a transient femoral nerve palsy. Both of these nerve palsies occurred in patients operated by transgluteal approach who had congenital hip dislocation and histories of multiple hip surgeries in childhood. Retraction of the nonelastic fibrous tissue containing the femoral nerve required to visualize the acetabulum may have contributed to this transient palsy as reported in similar cases [27]. In 1 case of cemented hip replacement performed through the posterolateral approach, a sciatic nerve palsy resulted from inadvertent entrapment of the nerve in the suture. In this patient the wound was explored early after the operation because of intractable neurogenic pain and the nerve was released, which resulted in gradual nearly complete recovery.

\section{Conclusion}

Our data showed that cementless implants had better clinical results and a lower loosening rate of the acetabular components at 3 years of follow-up compared to cemented implants at 5 years of follow-up. During the studied follow-up period cemented femoral implants were equally stable compared to cementless femoral implants. Further prospective follow-up is necessary to validate these results. 


\section{References}

-1 Garbuz DS, Xu M: Patient's outcome after total hip arthroplasty. J Arthroplasty 2006;21: 998-1004.

$>2$ Kim YH: Bilateral cemented and cementless total hip arthroplasty. J Arthroplasty 2002; 17:434-440.

$\checkmark 3$ Laupacis A, Bourne R, Rorabeck C, Fenny D, Tugwell P, Wong C: Comparison of total hip arthroplasty performed with and without cement. J Bone Joint Surg 2002;84A:18231828.

4 Zimmerman S, Hawkes WG, Hudson JI, Magaziner J, Hebel JR, Towheed T, Gardner J, Provenzano G, Kenzora JE: Outcomes of surgical management of total hip replacement in patients aged 65 and older: cemented versus cementless femoral components and lateral or anterolateral versus posterior anatomical approach. J Orthop Res 2002;20: 182-191.

$\checkmark 5$ Kim HY, Kook HK, Kim JS: Total hip replacement with a cementless acetabular component and a cemented femoral component in patients younger than fifty years old. J Bone Joint Surg 2002;84A:770-774.

6 Merle d'Aubigne R, Postel M: Functional results of hip arthroplasty with acrylic prosthesis. J Bone Joint Surg 1954;76A:129-138.

7 DeLee JG, Charnley J: Radiological demarcation of cemented sockets in total hip replacement. Clin Orthop 1976;121:20-32.

$>8$ Gruen TA, McNeice GM, Amstutz HC: Modes of failure of cemented stem-type femoral components: a radiographic analysis of loosening. Clin Orthop 1979;141:17-27.

$>9$ Delaunay C, Cazeau C, Kapandji AI: Cementless primary total hip replacement. Intern Orthop 1998;22:1-5.
10 Schroeder HJ, Matziolis G, Tuischer J, Leut loff D, Duda GN, Perka C: J Arthroplasty 2006;21:497-502.

11 Pettersson H, Gentz CF, Lindberg HO, Carlsson AS: Radiologic evaluation of the position of the acetabular component of the total hip prosthesis. Acta Radiol Diagn (Stockh) 1982; 23:259-263.

12 Pieringer H, Auersperg V, Bohler N: Longterm results of the cementless Alloclassic hip arthroplasty using a $28-\mathrm{mm}$ ceramic head. J Arthroplasty 2006;21:967-974.

13 Clohisy JC, Harris WH: Matched-pair analysis of cemented and cementless acetabular reconstruction in primary total hip arthroplasty. J Arthroplasty 2001;16:697-705.

14 Emerson RH, Head WC, Emerson CB, Rosenfeldt W, Higgins LL: A comparison of cemented and cementless titanium femoral components used for primary total hip arthroplasty. J Arthroplasty 2002;17:584-591.

15 Gaffey JL, Callaghan JJ, Pedersen DR, Goetz DD, Sulliva PM, Johnston RC: Cementless acetabular fixation at fifteen years. J Bone Joint Surg 2004;86A:257-261.

16 Ritter MA, Thong AE: The role of cemented sockets in 2004. J Arthroplasty 2004;19 (suppl 1):92-94.

17 Sanchez-Sotelo J, Berry DJ: Epidemiology of instability after total hip replacement. Orthop Clin North Am 2001;32:543-552.

18 Paterno SA, Lachiewicz PF, Kelley S: The influence of patient-related factors and the position of the acetabular component on the rate of dislocation after total hip replacement. J Bone Joint Surg 1997;79A:12021210 .
19 Scifert CF, Noble PC, Brown TD, Bartz RL, Kadakia N, Sugano N, Johnston RC, Pedersen DR, Callaghan JJ: Experiments and computational simulation of total hip arthroplasty dislocation. Orthop Clin North Am 2001;32:553-567.

20 Phillips CB, Barrett JA, Losina E, Mahomed NN, Lingard EA, Gudagnoli E, Baron JA, Harris WH, Poss R, Katz JN: Incidence rates of dislocation, pulmonary embolism, and deep infection during the first six months after elective total hip replacement. J Bone Joint Surg 2003;85A:20-26.

21 Bourne RB, Mehin R: The dislocating hip: what to do, what to do. J Arthroplasty 2004; 19(suppl 1):111-114.

22 Blom AW, Taylor AH, Pattison G, Whitehouse S, Bannister GC: Infection after total hip arthroplasty. J Bone Joint Surg 2003; 85B:956-959.

23 Mahomed NN, Barrett JA, Katz JN, Phillips $\mathrm{CB}$, Losina E, Guadagnoli E, Harris WH, Poss R, Baron JA: Rates and outcomes of primary and revision total hip replacement in the United States Medicare population. J Bone Joint Surg 2003;85A:27-32.

24 Phillips JE, Crane TP, Noy M, Elliott TS, Grimer RJ: The incidence of deep prosthetic infections in a specialist or thopedic hospital. J Bone Joint Surg 2006;88B:943-948.

25 Ridgeway S, Wilson J, Charlet A, Kafatos G, Pearson A, Coello R: Infection of the surgical site after arthroplasty of the hip. J Bone Joint Surg 2005;87B:844-850.

26 Farrell CM, Springer BD, Haidukewych GJ, Morrey BF: Motor nerve palsy following primary total hip arthroplasty. J Bone Joint Surg 2005;87A:2619-2625.

$\checkmark 27$ Hartofilakidis G, Karachalios T: Total hip arthroplasty for congenital hip disease. J Bone Joint Surg 2004;86A:242-250. 